\title{
PEMODELAN PENDERITA STROKE DAN DIABETES MELITUS DI KOTA PADANG DENGAN MODEL REGRESI LOGISTIK BINER BIVARIAT
}

\author{
DHIYA ANISAH YUNARDI, MAIYASTRI, HAZMIRA YOZZA \\ Program Studi S1 Matematika, \\ Fakultas Matematika dan Ilmu Pengetahuan Alam, Universitas Andalas, \\ Kampus UNAND Limau Manis Padang, Indonesia. \\ email : dhiyaanisah98@gmail.com,maiyastri@sci.unand.ac.id,hazmirayozza@sci.unand.ac.id
}

Diterima 15 September 2020 Direvisi 14 Oktober 2020 Dipublikasikan 21 Oktober 2020

\begin{abstract}
Abstrak. Stroke dan diabetes merupakan penyakit dengan angka kematian tertinggi di Indonesia. Kedua penyakit ini memiliki hubungan yang cukup erat dan diduga disebabkan oleh faktor-faktor yang sama. Pada penelitian ini akan dianalisa faktor-faktor yang memengaruhi kejadian stroke dan diabetes melitus secara bersama di Kota Padang. Analisis dilakukan dengan analisis regresi logitstik biner bivariat. Data yang digunakan pada penelitian ini diambil dari data Riskesdas Provinsi Sumatra Barat tahun 2013. Penelitian ini menggunakan 8 variabel prediktor, yaitu jenis kelamin, usia, pendidikan terakhir, status pekerjaan, kebiasaan merokok, indeks massa tubuh (IMT), tekanan darah sistolik, dan tekanan darah diastolik. Langkah awal dalam penelitian adalah mendeskripsikan karakteristik penderita stroke dan diabetes melitus dengan masingmasing variabel prediktor, selanjutnya melakukan uji Chi-Square untuk mencari hubungan antara dua variabel respon. Kemudian dilakukan analisis Regresi Logistik Biner Bivariat untuk mengetahui model akhir. Analisis regresi logistik biner bivariat dilakukan dengan pengujian signifikansi parameter bivariat secara serentak dan parsial. Hasil dari pengujian signifikansi parameter bivariat, menunjukkan bahwa dari kedelapan variabel prediktor, hanya variabel kebiasaan merokok yang berpengaruh secara signifikan terhadap kejadian stroke dan diabetes melitus di Kota Padang.
\end{abstract}

Kata Kunci: Diabetes melitus, regresi logistik biner bivariat, stroke

\section{Pendahuluan}

Stroke dan diabetes memiliki hubungan yang cukup erat. Penderita diabetes rentan terkena komplikasi penyakit stroke jika penderita diabetes tersebut tidak dapat mengendalikan penyakitnya. Selain itu, kedua penyakit ini diduga disebabkan oleh faktor-faktor yang sama. Dari beberapa penelitian, stroke disebabkan oleh jenis kelamin, usia, pendidikan, pekerjaan, kebiasaan merokok, indeks massa tubuh, dan tekanan darah. Begitu pula dengan diabetes, dari beberapa penelitian, penyakit ini disebabkan oleh faktor yang sama. Pada penelitian ini akan dianalisa faktor

*penulis korespondensi 
yang memengaruhi kejadian stroke dan diabetes melitus secara bersama di Kota Padang. Analisis dilakukan dengan analisis regresi logitstik biner bivariat. Analisis regresi logistik biner bivariat dipilih karena akan dianalisa hubungan antara dua variabel respon dan beberapa variabel prediktor yang sama-sama memengaruhi kedua variabel respon tersebut. Variabel responnya berupa data kualitatif dikotomi yang bernilai 1 dan 0 . Keuntungan menggunakan regresi logistik biner bivariat adalah didapatkan model untuk masing-masing respon. Selain itu, nilai odds ratio yang didapatkan dapat menggambarkan hubungan antar variabel respon. Model regresi logistik biner bivariat pernah diterapkan oleh Siswadi ([6]) untuk menguji mengenai partisipasi anak dalam kegiatan ekonomi dan sekolah. Kemudian Fitriany ([2]) menguji mengenai karakteristik anak autisme terhadap keberhasilan terapi ABA pada kemampuan komunikasi verbal dan hubungan dengan orang lain.

\section{Landasan Teori}

\subsection{Regresi Logistik Biner Bivariat}

Regresi logistik biner bivariat merupakan pengembangan dari model regresi logistik biner. Yang membedakan regresi logistik biner dan regresi logistik biner bivariat adalah jumlah variabel respon, dimana regresi logistik biner digunakan jika hanya dimiliki satu variabel respon sedangkan regresi logistik biner bivariat digunakan jika terdapat dua variabel respon. Kedua variabel respon pada regresi logistik biner bivariat diasumsikan saling berhubungan dan memiliki dua kategori (biner) [4].

Misalkan terdapat dua variabel acak bivariat $Y_{1}$ dan $Y_{2}$ yang masing-masing bernilai 0 dan 1 dan saling berhubungan, maka $Y_{11}, Y_{10}, Y_{01}, Y_{00}$ secara berturutturut merupakan variabel yang berhubungan dengan variabel acak bivariat bernilai $(1,1),(1,0),(0,1),(0,0)$. Fungsi kepekatan peluang bersama dari kedua peubah acak diberikan oleh tabel berikut [7].

Tabel 1. Fungsi Kepekatan Peluang Bersama Peubah Acak Bivariat

\begin{tabular}{|c|c|c|c|}
\hline & $Y_{2}=1$ & $Y_{2}=0$ & $P\left(Y_{1}=y_{1}\right)$ \\
\hline$Y_{1}=1$ & $\pi_{11}$ & $\pi_{10}$ & $\pi_{1}$ \\
\hline$Y_{1}=0$ & $\pi_{01}$ & $\pi_{00}$ & $1-\pi_{1}$ \\
\hline$P\left(Y_{2}=y_{2}\right)$ & $\pi_{2}$ & $1-\pi_{2}$ & 1 \\
\hline
\end{tabular}

Berdasarkan Tabel 1, variabel acak bivariat $Y_{11}, Y_{10}, Y_{01}, Y_{00}$ memiliki probabilitas sebagai berikut.

$$
\begin{aligned}
& \pi_{11}=P\left(Y_{1}=1, Y_{2}=1\right), \\
& \pi_{10}=P\left(Y_{1}=1, Y_{2}=0\right), \\
& \pi_{01}=P\left(Y_{1}=0, Y_{2}=1\right), \\
& \pi_{00}=P\left(Y_{1}=0, Y_{2}=0\right) .
\end{aligned}
$$

Peluang marjinal untuk $Y_{1}=1$ dinotasikan dengan $\pi_{1}=P\left(Y_{1}=1\right)$ sedangkan peluang marjinal untuk $Y_{2}=1$ dinotasikan dengan $\pi_{2}=P\left(Y_{2}=1\right)$. Jika terdapat 
$k$ variabel prediktor maka dapat dituliskan nilai fungsi dari peluang marjinal $\pi_{1}(x)$ dan $\pi_{2}(x)$ sebagai berikut.

$$
\begin{aligned}
& \pi_{1}(x)=\frac{\exp \left(\beta_{01}+\beta_{11} x_{1}+\cdots+\beta_{k 1} x_{k}\right)}{1+\exp \left(\beta_{01}+\beta_{11} x_{1}+\cdots+\beta_{k 1} x_{k}\right)}, \\
& \pi_{2}(x)=\frac{\exp \left(\beta_{02}+\beta_{12} x_{1}+\cdots+\beta_{k 2} x_{k}\right)}{1+\exp \left(\beta_{02}+\beta_{12} x_{1}+\cdots+\beta_{k 2} x_{k}\right)} .
\end{aligned}
$$

Untuk mendapatkan nilai $\boldsymbol{\beta}$, maka Persamaan 2.1 dan 2.2 ditransformasi dengan transformasi logit sehingga diperoleh fungsi $g(x)$ yang linier dalam parameternya [3]. Model transformasi logit untuk $i=1,2$ adalah sebagai berikut.

$$
g_{i}(x)=\ln \left(\frac{\pi_{i}(x)}{1-\pi_{i}(x)}\right)=\beta_{0 i}+\beta_{1 i} x_{1}+\cdots+\beta_{k i} x_{k}=\boldsymbol{\beta}_{i}{ }^{T} \boldsymbol{x} .
$$

Model regresi logistik biner bivariat dinyatakan oleh fungsi logit $g_{1}(x)$ dan logit $g_{2}(x)$ sebagai berikut

$$
\begin{aligned}
& g_{1}(x)=\ln \left(\frac{\pi_{1}(x)}{1-\pi_{1}(x)}\right)=\beta_{01}+\beta_{11} x_{1}+\cdots+\beta_{k 1} x_{k}=\boldsymbol{\beta}_{\mathbf{1}}{ }^{T} \boldsymbol{x} \\
& g_{2}(x)=\ln \left(\frac{\pi_{2}(x)}{1-\pi_{2}(x)}\right)=\beta_{02}+\beta_{12} x_{1}+\cdots+\beta_{k 2} x_{k}=\boldsymbol{\beta}_{\mathbf{2}}{ }^{T} \boldsymbol{x},
\end{aligned}
$$

dimana $k$ adalah banyaknya variabel prediktor, $\boldsymbol{\beta}_{\mathbf{1}}=\left[\beta_{01}, \beta_{11}, \beta_{21}, \cdots, \beta_{k 1}\right]^{T}, \boldsymbol{\beta}_{\mathbf{2}}=$ $\left[\beta_{02}, \beta_{12}, \beta_{22}, \cdots, \beta_{k 2}\right]^{T}$ dan $\boldsymbol{x}=\left[1, x_{1}, \cdots, x_{k}\right]^{T}$.

Lambang $\psi$ merupakan nilai odds ratio yang menunjukkan bahwa terdapat hubungan antar variabel respon. Dari Tabel 1 diperoleh nilai odds ratio sebagai berikut

$$
\psi=\frac{\pi_{11} \pi_{00}}{\pi_{10} \pi_{01}}
$$

dengan $\psi \geq 0$ jika $Y_{1}$ dan $Y_{2}$ tidak saling bebas, apabila $\psi=1$ maka $Y_{1}$ dan $Y_{2}$ saling bebas karena tidak ada hubungan antar variabel respon [1]. Selanjutnya $\ln (\psi)=\theta$ dengan $\theta=\gamma^{T} x$ dimana $\gamma$ merupakan vektor parameter terikat. $\theta$ merupakan model transformasi odds ratio dimana

$$
\theta=\ln \left(\frac{\pi_{11} \pi_{00}}{\pi_{10} \pi_{01}}\right)=\gamma_{0}+\gamma_{1} x_{1}+\cdots+\gamma_{k} x_{k}=\gamma^{T} x
$$

Menurut [5], peluang $\pi_{11}$ didefinisikan oleh $\pi_{1}, \pi_{2}$, dan $\psi$ sebagai berikut

$$
\pi_{11}= \begin{cases}\frac{1}{2}(\psi-1)^{-1}\left(a-\sqrt{a^{2}+b}\right) & ; \psi \neq 1 \\ \pi_{1} \pi_{2} & ; \psi=1\end{cases}
$$

dimana $a=1+\left(\pi_{1}+\pi_{2}\right)(\psi-1)$ dan $b=-4 \psi(\psi-1) \pi_{1} \pi_{2}$. Tiga peluang lain $\pi_{10}, \pi_{01}, \pi_{00}$ diperoleh dari peluang marjinal $\pi_{1}, \pi_{2}$ dan $\pi_{11}$ sebagai berikut.

$$
\begin{aligned}
& \pi_{10}=\pi_{1}-\pi_{11}, \\
& \pi_{01}=\pi_{2}-\pi_{11}, \\
& \pi_{00}=1-\pi_{11}-\pi_{10}-\pi_{01} .
\end{aligned}
$$




\subsection{Pendugaan Parameter Regresi Logistik Biner Bivariat}

Pendugaan parameter regresi logistik biner bivariat dilakukan dengan menggunakan metode Maximum Likelihood Estimation (MLE). Metode ini digunakan karena distribusi dari variabel acak biner bivariatnya diketahui, yaitu berdistribusi binomial. Pendugaan parameter diperoleh dengan memaksimumkan fungsi likelihood [4].

Pada data biner bivariat, dengan mengambil $n$ sampel acak yang saling bebas, maka variabel acak biner bivariat $\left(Y_{1 i}, Y_{2 i}\right)$ dimana $i=1,2, \ldots, n$ akan identik dengan variabel acak bivariat $\left(Y_{11}, Y_{10}, Y_{01}, Y_{00}\right)$ yang berdistribusi binomial dengan nilai peluang $\pi_{11}, \pi_{10}, \pi_{01}, \pi_{00}$. Fungsi likelihood dari variabel acak bivariat adalah sebagai berikut [1].

$$
\begin{aligned}
L(\boldsymbol{\beta}) & =\prod_{i=1}^{n} \pi\left(Y_{11 i}=y_{11 i}, Y_{10 i}=y_{10 i}, Y_{01 i}=y_{01 i}, Y_{00 i}=y_{00 i}\right) \\
& =\prod_{i=1}^{n} \pi_{11}^{y_{11 i}} \pi_{10}^{y_{10 i}} \pi_{01}^{y_{01 i}} \pi_{00}^{y_{00 i}}
\end{aligned}
$$

Selanjutnya dibentuk fungsi log-natural likelihoodnya dengan melogaritma naturalkan fungsi likelihood diatas seperti berikut

$$
\begin{aligned}
\ln L(\boldsymbol{\beta}) & =\ln \left(\prod_{i=1}^{n} \pi_{11}^{y_{11 i}} \pi_{10}^{y_{10 i}} \pi_{01}^{y_{01 i}} \pi_{00}^{y_{00 i}}\right) \\
& =\sum_{i=1}^{n}\left(y_{11 i} \ln \pi_{11}+y_{10 i} \ln \pi_{10}+y_{01 i} \ln \pi_{01}+y_{00 i} \ln \pi_{00}\right)
\end{aligned}
$$

Untuk menaksir nilai parameter $\hat{\boldsymbol{\beta}}$, dimana $\hat{\boldsymbol{\beta}}=\left(\hat{\beta}_{1}, \hat{\beta}_{2}, \hat{\theta}\right)$, dilakukan dengan memaksimumkan fungsi log-natural likelihoodnya, yaitu dengan menghitung turunan pertama dari fungsi log-natural likelihood kemudian disamadengankan nol.

$$
\frac{\partial \ln L(\boldsymbol{\beta})}{\partial \boldsymbol{\beta}}=\sum_{i=1}^{n}\left(\frac{y_{11 i}}{\pi_{11}} \frac{\partial \pi_{11}}{\partial \boldsymbol{\beta}}+\frac{y_{10 i}}{\pi_{10}} \frac{\partial \pi_{10}}{\partial \boldsymbol{\beta}}+\frac{y_{01 i}}{\pi_{01}} \frac{\partial \pi_{01}}{\partial \boldsymbol{\beta}}+\frac{y_{00 i}}{\pi_{00}} \frac{\partial \pi_{00}}{\partial \boldsymbol{\beta}}\right)
$$

Nilai standar deviasi dari penaksir parameter $\hat{\boldsymbol{\beta}}$ dapat diketahui dari matriks varians kovarians. Nilai varians kovarians diperoleh dari ekspektasi turunan kedua fungsi log-natural likelihood yang dimaksimumkan kemudian disamadengankan nol. Turunan keduanya digunakan untuk menaksir nilai standar deviasi dari penaksir parameter $\hat{\boldsymbol{\beta}}$

$$
\begin{aligned}
\frac{\partial^{2} \ln L(\boldsymbol{\beta})}{\partial \boldsymbol{\beta} \partial \boldsymbol{\beta}^{T}}=\sum_{i=1}^{n} & \left\{\left(-\frac{y_{11 i}}{\pi_{11}} \frac{\partial \pi_{11}}{\partial \boldsymbol{\beta}^{T}} \frac{\partial \pi_{11}}{\partial \boldsymbol{\beta}}+\frac{y_{11 i}}{\pi_{11}} \frac{\partial^{2} \pi_{11}}{\partial \boldsymbol{\beta} \partial \boldsymbol{\beta}^{T}}\right)+\right. \\
& \left(-\frac{y_{10 i}}{\pi_{10}} \frac{\partial \pi_{10}}{\partial \boldsymbol{\beta}^{T}} \frac{\partial \pi_{10}}{\partial \boldsymbol{\beta}}+\frac{y_{10 i}}{\pi_{10}} \frac{\partial^{2} \pi_{10}}{\partial \boldsymbol{\beta} \partial \boldsymbol{\beta}^{T}}\right)+ \\
& \left(-\frac{y_{01 i}}{\pi_{01}} \frac{\partial \pi_{01}}{\partial \boldsymbol{\beta}^{T}} \frac{\partial \pi_{01}}{\partial \boldsymbol{\beta}}+\frac{y_{01 i}}{\pi_{01}} \frac{\partial^{2} \pi_{01}}{\partial \boldsymbol{\beta} \partial \boldsymbol{\beta}^{T}}\right)+ \\
& \left.\left(-\frac{y_{00 i}}{\pi_{00}} \frac{\partial \pi_{00}}{\partial \boldsymbol{\beta}^{T}} \frac{\partial \pi_{00}}{\partial \boldsymbol{\beta}}+\frac{y_{00 i}}{\pi_{00}} \frac{\partial^{2} \pi_{00}}{\partial \boldsymbol{\beta} \partial \boldsymbol{\beta}^{T}}\right)\right\}
\end{aligned}
$$


Pendugaan untuk $\boldsymbol{\beta}$ pada persamaan 2.10 tidak dapat diperoleh secara langsung, karena fungsi yang dihasilkan berbentuk implisit sehingga diperlukan metode iterasi Newton Raphson.

\subsection{Pengujian Parameter Regresi Logistik Biner Bivariat}

Pengujian signifikansi parameter dilakukan untuk mengetahui apakah parameter yang terdapat di dalam model berpengaruh secara signifikan atau tidak. Pengujian signifikansi ini dilakukan secara keseluruhan (serentak) dan individu (parsial) [3]. Pengujian signifikansi secara serentak dilakukan untuk mengetahui apakah variabel prediktor secara bersama-sama memengaruhi model atau tidak. Pengujian secara serentak dilakukan menggunakan uji rasio likelihood, dengan hipotesis sebagai berikut.

$$
\begin{aligned}
& H_{0}: \beta_{11}=\beta_{21}=\cdots=\beta_{k 1}=\beta_{12}=\cdots=\beta_{k 2}=0, \\
& H_{1}: \text { minimal terdapat satu } \beta_{r s} \neq 0, \text { dengan } r=1,2, \cdots, k \text { dan } s=1,2 .
\end{aligned}
$$

Tolak $H_{0}$ jika $\frac{L(\hat{\omega})}{L(\hat{\Omega})}<\mu_{0}<1$ dimana $0<\mu_{0}<1$.

Statistik uji :

$$
\begin{aligned}
G= & -2 \ln \left[\frac{L(\hat{\omega})}{L(\hat{\Omega})}\right]=2 \ln L(\hat{\Omega})-2 \ln L(\hat{\omega}) \\
= & 2 \sum_{i=1}^{n}\left[y_{11} \ln \pi_{11}+y_{10} \ln \pi_{10}+y_{01} \ln \pi_{01}+y_{00} \ln \pi_{00}\right] \\
& -2 \sum_{i=1}^{n}\left[y_{11} \ln \left(n_{11}\right)+y_{10} \ln \left(n_{10}\right)+y_{01} \ln \left(n_{01}\right)+y_{00} \ln \left(n_{00}\right)-n \ln (n)\right]
\end{aligned}
$$

Statistik uji $G$ mengikuti distribusi $C h i$-Square sehingga keputusan tolak $H_{0}$ jika nilai $G>\chi_{(\alpha, v)}^{2}$, dimana $v$ adalah banyaknya parameter model dibawah populasi dikurangi banyaknya parameter model dibawah $H_{0}$. Nilai $\chi_{(\alpha, v)}^{2}$ dapat diperoleh dari tabel Chi-Square.

Pengujian signifikansi secara parsial dilakukan untuk mengetahui apakah variabel prediktor secara individu memengaruhi model atau tidak. Pengujian secara parsial dilakukan menggunakan uji Wald, dengan hipotesis sebagai berikut.

$$
\begin{aligned}
& H_{0}: \beta_{r s}=0, \\
& H_{1}: \beta_{r s} \neq 0
\end{aligned}
$$

dengan $r=0,1,2, \cdots, k$ dan $s=1,2$.

Statistik uji sebagai berikut.

$$
W=\frac{\hat{\beta}_{r s}}{S E\left(\hat{\beta}_{r s}\right)},
$$

dengan nilai $r=0,1,2, \ldots, k$ dan $s=1,2$, dimana $\hat{\beta}_{r s}$ merupakan nilai penduga dari $\beta_{r s}$ yang diperoleh dari metode maksimum likelihood dan $S E\left(\hat{\beta}_{r s}\right)$ merupakan standard error dari $\hat{\beta}_{r s}$. 
Keputusan tolak $H_{0}$ diperoleh jika nilai $W>Z_{\alpha / 2}$ atau jika nilai $W<-Z_{\alpha / 2}$ dimana nilai $Z_{\alpha / 2}$ diperoleh dari tabel distribusi normal dengan $\alpha=0.05$. Untuk kasus derajat bebas lebih dari satu, pengujian signifikansi secara parsial dilakukan menggunakan uji rasio likelihood dengan derajat bebas $v$ dan tolak $H_{0}$ jika nilai $G>\chi_{(\alpha, v)}^{2}[3]$.

\subsection{Stroke}

Stroke adalah penyakit yang terjadi pada otak berupa gangguan fungsi syaraf lokal dan/atau global yang muncul secara mendadak, progresif, dan cepat. Penyakit stroke dapat disebabkan oleh beberapa faktor. Berikut adalah faktor risiko yang dapat menyebabkan penyakit stroke.

(1) Jenis kelamin.

(2) Usia.

(3) Pendidikan Terakhir.

(4) Status Pekerjaan.

(5) Kebiasaan Merokok.

(6) Indeks Massa Tubuh (IMT).

(7) Tekanan Darah.

\subsection{Diabetes Melitus}

Diabetes melitus adalah penyakit yang menyerang metabolisme yang merupakan kumpulan gejala yang timbul karena adanya peningkatan kadar glukosa darah diatas nilai normal. Penyakit diabetes melitus dapat disebabkan oleh beberapa faktor. Berikut adalah faktor risiko yang dapat menyebabkan penyakit diabetes melitus.

(1) Jenis kelamin.

(2) Usia.

(3) Pendidikan Terakhir.

(4) Status Pekerjaan.

(5) Kebiasaan Merokok.

(6) Indeks Massa Tubuh (IMT).

(7) Tekanan Darah.

\section{Pembahasan}

\subsection{Pengujian Signifikansi Parameter Bivariat Secara Serentak}

Pengujian signisikansi parameter secara serentak ini dilakukan untuk mengetahui apakah variabel prediktor secara bersama-sama memengaruhi model atau tidak. Hipotesis uji signifikansi parameter secara serentak sebagai berikut.

$$
\begin{aligned}
& H_{0}: \beta_{11}=\beta_{21}=\cdots=\beta_{k 1}=\beta_{12}=\cdots=\beta_{k 2}=0, \\
& H_{1}: \text { minimal ada satu } \beta_{r s} \neq 0, \text { dengan } r=1,2, \ldots, k \text { dan } s=1,2 .
\end{aligned}
$$

$H_{0}$ ditolak jika nilai $G>\chi_{(0,05, v)}^{2}$. Hasil pengujian signifikansi parameter secara serentak dengan menggunakan Persamaan 2.13 adalah sebagai berikut. 
Dhiya Anisah Yunardi, dkk.

Tabel 2. Pengujian Signifikansi Parameter Regresi Logistik Biner Bivariat Secara Serentak

\begin{tabular}{|c|c|c|}
\hline Nilai $G$ & $d f$ & Nilai Chi-Square Tabel \\
\hline 97,1845 & 51 & $\chi_{(0,05 ; 51)}=68,67$ \\
\hline
\end{tabular}

Berdasarkan Tabel 2 dapat dilihat bahwa nilai $G$ lebih besar dari nilai $C h i$ Square Tabel. Hal ini menyatakan bahwa $H_{0}$ ditolak, yang artinya minimal ada satu variabel prediktor yang memengaruhi model.

\subsection{Pengujian Signifikansi Parameter Bivariat Secara Parsial}

Setelah dilakukan pengujian signifikansi parameter secara serentak, selanjutnya dilakukan pengujian signifikansi parameter secara parsial untuk mengetahui variabel prediktor apa yang berpengaruh secara signifikan terhadap model.

Tabel 3. Pengujian Signifikansi Parameter Regresi Logistik Biner Bivariat Secara Parsial

\begin{tabular}{|c|c|c|c|c|c|}
\hline Variabel & Kategori & Parameter & Koefisien & Wald & $P$-value \\
\hline \multirow{15}{*}{ Kebiasaan Merokok } & \multirow{3}{*}{ Konstanta } & $\beta_{01}$ & 4,742 & 4,524 & $6,06 e-06$ \\
\hline & & $\beta_{02}$ & 4,171 & 6,628 & $3,40 e-11$ \\
\hline & & $\gamma_{0}$ & 2,055 & 0,747 & 0,455 \\
\hline & \multirow{3}{*}{$X_{5(1)}$} & $\beta_{11}$ & 0,090 & 0,160 & 0,873 \\
\hline & & $\beta_{12}$ & $-0,219$ & $-0,703$ & 0,482 \\
\hline & & $\gamma_{1}$ & 0,422 & 0,313 & 0,755 \\
\hline & \multirow{3}{*}{$X_{5(2)}$} & $\beta_{21}$ & 0,052 & 0,034 & 0,973 \\
\hline & & $\beta_{22}$ & $-0,122$ & $-0,132$ & 0,895 \\
\hline & & $\gamma_{2}$ & $-0,256$ & $-0,062$ & 0,951 \\
\hline & \multirow{3}{*}{$X_{5(3)}$} & $\beta_{31}$ & $-0,019$ & $-0,033$ & 0,974 \\
\hline & & $\beta_{32}$ & 0,044 & 0,122 & 0,903 \\
\hline & & $\gamma_{3}$ & 0,049 & 0,030 & 0,976 \\
\hline & \multirow{3}{*}{$X_{5(4)}$} & $\beta_{41}$ & $-0,013$ & $-0,018$ & 0,986 \\
\hline & & $\beta_{42}$ & 0,036 & 0,082 & 0,935 \\
\hline & & $\gamma_{4}$ & 0,095 & 0,048 & 0,962 \\
\hline
\end{tabular}

Hasil dari Tabel 3 menunjukkan bahwa variabel kebiasaan merokok berpengaruh terhadap model. Hal ini ditunjukkan dari nilai Likelihood Ratio Test $(G)$ sebesar 32,0314 dengan $d f=9$. Nilai ini lebih besar dari nilai $\chi^{2}$ tabel pada taraf nyata 0,05 dan derajat bebas 9 yaitu 16,919.

Berdasarkan hasil pengujian signifikansi parameter secara parsial, diperoleh variabel kebiasaan merokok yang berpengaruh terhadap model. Model akhir regresi logistik biner bivariat yang terbentuk adalah sebagai berikut.

Model $\operatorname{logit} 1$ :

$$
\begin{aligned}
\ln \left(\frac{\pi_{1}(x)}{1-\pi_{1}(x)}\right) & =\beta_{01}+\beta_{11} x_{5(1)}+\beta_{21} x_{5(2)}+\beta_{31} x_{5(3)}+\beta_{41} x_{5(4)} \\
& =4,742+0.090 x_{5(1)}+0.052 x_{5(2)}-0.019 x_{5(3)}-0.013 x_{5(4)}
\end{aligned}
$$


Model logit 2:

$$
\begin{aligned}
\ln \left(\frac{\pi_{2}(x)}{1-\pi_{2}(x)}\right) & =\beta_{02}+\beta_{12} x_{5(1)}+\beta_{22} x_{5(2)}+\beta_{32} x_{5(3)}+\beta_{42} x_{5(4)}, \\
& =4.171-0.219 x_{5(1)}-0.122 x_{5(2)}+0.044 x_{5(3)}+0.036 x_{5(4)} .
\end{aligned}
$$

Model transformasi odds ratio :

$$
\begin{aligned}
\ln \left(\frac{\pi_{11} \pi_{00}}{\pi_{10} \pi_{01}}\right) & =\gamma_{0}+\gamma_{1} x_{5(1)}+\gamma_{2} x_{5(2)}+\gamma_{3} x_{5(3)}+\gamma_{4} x_{5(4)}, \\
& =2.055+0.422 x_{5(1)}-0.256 x_{5(2)}+0.049 x_{5(3)}+0.095 x_{5(4)} .
\end{aligned}
$$

Model peluang marjinal $Y_{1}$ :

$$
\begin{aligned}
& \pi_{1}(x)=\frac{\exp \left(\beta_{01}+\beta_{11} x_{5(1)}+\beta_{21} x_{5(2)}+\beta_{31} x_{5(3)}+\beta_{41} x_{5(4)}\right)}{1+\exp \left(\beta_{01}+\beta_{11} x_{5(1)}+\beta_{21} x_{5(2)}+\beta_{31} x_{5(3)}+\beta_{41} x_{5(4)}\right)} \\
& =\frac{\exp \left(4,742+0.090 x_{5(1)}+0.052 x_{5(2)}-0.019 x_{5(3)}-0.013 x_{5(4)}\right)}{1+\exp \left(4,742+0.090 x_{5(1)}+0.052 x_{5(2)}-0.019 x_{5(3)}-0.013 x_{5(4)}\right)} \\
& \text { Model peluang marjinal } Y_{2} \text { : } \\
& \begin{aligned}
\pi_{2}(x) & =\frac{\exp \left(\beta_{02}+\beta_{12} x_{5(1)}+\beta_{22} x_{5(2)}+\beta_{32} x_{5(3)}+\beta_{42} x_{5(4)}\right)}{1+\exp \left(\beta_{02}+\beta_{12} x_{5(1)}+\beta_{22} x_{5(2)}+\beta_{32} x_{5(3)}+\beta_{42} x_{5(4)}\right)} \\
& =\frac{\exp \left(4.171-0.219 x_{5(1)}-0.122 x_{5(2)}+0.044 x_{5(3)}+0.036 x_{5(4)}\right)}{1+\exp \left(4.171-0.219 x_{5(1)}-0.122 x_{5(2)}+0.044 x_{5(3)}+0.036 x_{5(4)}\right)}
\end{aligned}
\end{aligned}
$$

\section{Kesimpulan}

Berdasarkan hasil pengujian signifikansi parameter bivariat, diperoleh variabel prediktor yang berpengaruh terhadap variabel respon adalah kebiasaan merokok $(X 5)$.

\section{Ucapan Terima kasih}

Terimakasih kepada Ibu Ferra Yanuar, Ibu Des Welyyanti dan Bapak Narwen yang telah memberikan masukan dan saran sehingga penelitian ini dapat diselesaikan dengan baik.

\section{Daftar Pustaka}

[1] Cessie, S., Houwelingen, J.C., 1994, Logistic Regression for Correlated Binary Data, Applied Statistic, Volume 43 No.1: 95 - 108

[2] Fitriany, M., 2014, Analisis Regresi Logistik Biner Bivariat Untuk Mengetahui Keberhasilan Terapi Aba Pada Kemampuan Komunikasi Verbal dan Hubungan dengan Orang Lain Anak Autisme, Skripsi di Universitas Diponegoro

[3] Hosmer, DW., Lemeshow, S., 2000, Applied Logistic Regression, Edisi ke-2, John Wiley \& Sons, Inc, Canada

[4] McCullagh, P.,Nelder, J.A., 1989, Generalized Linier Models, Edisi ke-2, Chapman \& Hall, London

[5] Palmgren, J., 1989, Regression Models for Bivariate Binary Responses, Technical Report 101, Seattle

[6] Siswadi, 2009, Analisis Regresi Logistik Biner Bivariat Pada Partisipasi Anak Dalam Kegiatan Ekonomi dan Sekolah di Jawa Timur, Thesis di Institut Teknologi Sepuluh November

[7] Spring, 2009, Modelling of African Farm Dynamics Using Bivariate Binary Logistic Regression in WinBUGS, Thesis in LUND University 